Discussion Paper No. 759

\title{
MEASUREMENT OF SOCIAL PREFERENCE FROM UTILITY-BASED CHOICE EXPERIMENTS
}

\author{
Katsunori Yamada \\ Masayuki Sato \\ Yasuhiro Nakamoto
}

November 2009

The Institute of Social and Economic Research

Osaka University

6-1 Mihogaoka, Ibaraki, Osaka 567-0047, Japan 


\title{
Measurement of Social Preference from Utility-Based Choice Experiments*
}

\author{
Katsunori Yamada $^{\dagger}$ Masayuki Sato ${ }^{\ddagger} \quad$ Yasuhiro Nakamoto ${ }^{\S}$
}

\begin{abstract}
Ever since the classical works of Smith and Veblen, economists have recognized that individuals care about their relative positions and status in addition to their own consumption. This paper addresses a new framework of choice experiments in order to specify the shape of utility function with preference externalities. Theoretical studies on social preference, which are conducted without estimating or calibrating important parameters of social preference and put forward various propositions in accordance with the parameters assumed, can refer to the parameters estimated in this paper. Our findings complement those of happiness studies which support the view of social preference. We show that preference externality is, on average, characterized by jealousy among Japanese respondents, and also that heterogeneity in social preference parameters is driven by differences in income levels, age, and gender.
\end{abstract}

Keywords: Social preference; Relative utility; Stated preferences; Choice experiment

JEL classifications: C25; D03; D62

\footnotetext{
${ }^{*}$ We would like to thank helpful comments from Hiroki Arato, Takahiro Ito, Fumio Ohtake, and seminar participants at Kyoto university. Of course, any remaining errors are authors'. Nakamoto and Yamada are grateful for the research grant provided by the GCOE program entitled "Human Behavior and Socioeconomic Dynamics" of Osaka University.

${ }^{\dagger}$ Corresponding author: Institute of Social and Economic Research, Osaka University, kyamada@econ.osaka-u.ac.jp, Mihogaoka 6-1, Ibaraki 567-0047, Japan.

${ }^{\ddagger}$ Field Science Education and Research Center, Kyoto University, Yoshida Hon-machi, Sakyo-ku, Kyoto, 606-8501, Japan.

${ }^{\S}$ Faculty of Economics, Kyushu Sangyo University, 2-3-1 Matsukadai, Higashi-ku, Fukuoka, 813-8503, Japan.
} 


\section{Introduction}

In the literature of behavioral economics, important parameters have been estimated via experiments, and policy implications derived from theoretical studies addressing these parameters have shown a richness and more practical adaptation. Thus far, considerable progress has been made in fields such as environmental economics, health economics, and transportation economics. In this paper, we apply a choice experiment method in a survey experiment to the economics of social preference. Although the social preference effect has been recognized since the classical works of Adam Smith and Thorstein Veblen and despite the fact that there are a number of happiness studies in the literature that support the view of social preference, there is as yet no direct information on the shape of utility function with social preference. This paper bridges the gap between the theoretical and empirical studies on social preference by estimating the signs and magnitudes of preference parameters using conditional and mixed logit models. The techniques of choice experiments are, as far as we are aware, new to the literature of social preference. Theoretical studies with preference externality have provided different types of implications in accordance with differences in assumed parameters. However, we believe that such studies will be able to provide more practical policy implications in the future by addressing estimated parameters in choice experiments of the kind we provide in this paper.

Regarding the existence of social preferences, many studies on happiness regressions support the view in terms of jealousy effects. These studies include Clark and Oswald [1996], Alesina, Di Tella, and MacCulloch [2004], Luttmer [2005], Ferrer-i Carbonell [2005], and Clark, Kristensen, and Westergard-Nielsen [2009b]. ${ }^{1}$ On the other hand, some experimental studies support the view of social preference in the form of egalitarianism

\footnotetext{
${ }^{1}$ Senik [2004] showed that her proxies of reference wage affect happiness positively in a Russian data set. She argued this happened because the reference wage measures worked as signal devices rather than social comparison ones. In another study of happiness regressions that provided "admiration" results, Clark, Kristensen, and Westergard-Nielsen [2009a] argued that a social preference as a form of admiration resulted since they focused on comparison among neighbors, in which case reference income served as a proxy of social capital. See Frey and Stutzer [2001] and Frey and Stutzer [2002] for reviews of happiness studies in the literature. Also see Clark, Frijters, and Shields [2008] for an excellent review of happiness studies on social preference.
} 
(Fehr, Bernhard, and Rockenbach [2008]; Bartling, Fehr, Marechal, and Schunk [2009]). ${ }^{2}$ Since it is possible that with egalitarianism people favor improvements in the economic situation of others, egalitarianism can be related to "admiration". Moreover, recent developments in neuroscience have clarified the brain mechanism of social preferences (Fliessbach, Weber, Trautner, Dohmen, Sunde, Elger, and Falk [2007]; Fehr and Camerer [2007]). Hence, in general, evidence from many research fields supports the notion of social preferences. However, as previous studies have provided mixed results about the sign and magnitude of social preference effects, here we further investigate the issue using the strategy of choice experiments.

In a policy context of theoretical economics analyses, the existence of social preference has consequences on optimal tax decisions Oswald [1983]. Since social preference functions as an externality in competitive markets, welfare maximization in a society can be attained only with the knowledge of the direction and intensity of the effects (Corneo and Jeanne [1997]; Corneo and Jeanne [2001]). Also, it has been considered that social preference affects asset pricings in macro economies (Abel [1990]; Gali [1994]; Bakshi and Chen [1996]). However, without knowledge of the true parameters, we cannot determine whether the effects of social preference are large enough to have consequential effects on macroeconomic asset pricings. By introducing the choice experiments framework to the literature of social preference, we can obtain evidence which is directly applicable to theoretical studies of social preference. ${ }^{3}$ Moreover, by applying our strat-

\footnotetext{
${ }^{2}$ Interestingly, experiments on non-human animals, namely, chimpanzees, showed that they are not endowed with social preferences. See, for example, Silk and et al. [2005], Jensen, Hare, Call, and Tomasello [2006], and Jensen and Tomasello [2007].

${ }^{3}$ The reason why the literature of happiness studies cannot provide direct information on utility function is that dependent variables for the regressions of subjective well-being (SWB) are constructed from surveys which typically ask respondents to select levels of job or life satisfaction from a list of numbers. The selected numbers are then considered to be proxies of the levels of "utility". However, there has been some debate about interpretations of the nature of SWB, since researchers have not been sure whether it represents cardinal or ordinal utility (van Praag [1991]; Ferrer-i Carbonell and Frijters [2004]). Also, SWB measures of respondents will be influenced by many aspects of their life including individual characteristics and mood on the day of the survey Kahneman, Krueger, Schkade, Schwarz, and Stone [2006]. On the other hand, utility in a technical sense is considered to be dependent just upon consumption (and social status). This ambiguity about the coverage of SWB measures means that researchers cannot specify the shape of "utility function" from the SWB data, which encompasses measurement errors of utility.
} 
egy of choice experiments, we can overcome a problematic issue common to happiness studies of social preference: construction of the proxies of social preference in happiness regressions is difficult because people's determinations of reference groups are endogenous (de la Garza, Mastrobuoni, Sannabe, and Yamada [2009]). With our choice experiments, the endogeneity problem can be mitigated since the socio-economic situations and reference points are exogenously given.

In this paper, similar to Viscusi, Huber, and Bell [2008], we estimate important parameters associated with consumer preferences by using a random utility model, and conditional fixed-effects logit and mixed logit models. The data for our study was collected using a survey methodology rather than using an experimental structure. ${ }^{4}$ The cohort profile of our study sample mirrored the Japanese census statistics, and for this sample we estimated the parameters in utility function which regulate preference externalities. A major difference between Viscusi et al. [2008] and our paper is that Viscusi et al. [2008] used a structural setting to infer parameters from estimates in conditional logit models while we use a reduced-form formulation and impose normalizing assumptions on scale parameters to specify preference parameters from our estimates. In this sense, our method may be more akin to that of Ida and Goto [2009] in which time and risk preference parameters are estimated using a reduced-form setting. Whereas Ida and Goto [2009] presume that the scale parameters are equal to one, in this paper, we make preferred normalizing assumptions on them and specify the shape of utility function with social preference. ${ }^{5}$

The major findings presented in this paper can be summarized as follows. First, from the conditional logit model, preference externality is characterized by jealousy rather than

\footnotetext{
${ }^{4}$ Experimental studies on game theory and social preference include Charness and Rabin [2002].

${ }^{5}$ See Train [2003] for the interpretations of scale parameters in conditional logit models. We argue that our strategy is more appropriate than that in Ida and Goto [2009] where the full sample is divided into subgroups and preference parameters are estimated separately in each sub-group. With their methodology, if scale parameters, which are unknown to researchers, are different across sub-groups, we cannot directly compare estimates coming from the different sub-groups. With our data set, although not shown in this paper, it was confirmed, with heteroscedastic logit models, that there are significant differences in the scale parameters across sub-groups of different individual characteristics. The structural setting in Viscusi et al. [2008] is much superior regarding this point since normalizing assumptions on scale parameters are not required in their framework.
} 
admiration among Japanese respondents. Second, we obtain that the welfare loss in a competitive symmetric equilibrium caused by the preference externality is around 2.6 percent, compared to the social optimum. We argue that the intensity of market inefficiency resulting from social preference is comparable to that resulting from inflation and price rigidity. Thirdly, we consider the heterogeneity of preference parameters. Using a mixed logit model, we obtain that 64.4 percent of our study sample have negative preference externality (jealousy), and that the remaining 35.6 percent have positive preference externality (admiration). We also consider preference parameter heterogeneity caused by demographic differences. We show that heterogeneity in social preference parameters is driven by differences in income levels, age, and gender.

The rest of the paper is organized as follows. Section 2 provides a description of our data set and introduces the choice task in which respondents make socio-economic situation choices. We also provide evidence of the existence of social preference among respondents from happiness regressions. Section 3 describes the features of the random utility model and provides baseline preference parameters from the conditional logit model. In section 4, we consider the heterogeneity of preference parameters across individuals by using the mixed logit model, and by using the conditional logit model with dummy interactions. Section 5 provides some concluding remarks and the Appendices present the results of rationality tests and scope tests.

\section{Data}

\subsection{Structure of dataset}

Our data set is taken from an original Web-based survey conducted in March 2009. A Japanese consumer monitoring company, whose total number of registered subjects is around 990,000, conducted the survey. Japanese subjects aged between 18 and 69 were chosen at random from the population such that the cohort profile of our study sample 
mirrored the Japanese census statistics. The company distributed the survey to 2,859 monitors and 1,043 of them completed the survey. The average investigation time to finish the survey was 18 minutes 30 seconds. Each respondent who completed the survey was paid about 800 yen (about 8 US dollars). Because each respondent was asked to respond to eight situation choice tasks repeatedly, the number of observations from our choice experiment is 8,344 at maximum. We removed observations if they did not provide sufficient information. ${ }^{6}$

Descriptive statistics of the entire sample are shown in Table 1. Women account for around 48 percent of the entire sample. Mean age of the respondents is 44.9 years and 66 percent of the entire sample is married. Regarding educational attainment, 3 percent of the sample completed middle school only, 33 percent completed high school, and 39 percent pursued more advanced studies. The remaining 25 percent of the sample holds other degrees including those from technical and 2-year college programs. We do not see a big demographic difference between men and women except in the case of college and post doctoral attainments.

\subsection{Choice tasks}

In the survey, each subject considered socio-economic situation choice tasks. Before the respondents completed the repeated choice tasks, they answered two questions related to social comparison. The first question concerned self-assessment on attitude toward social comparison in the form of pecuniary rat races. The question was phrased as "Are you conscious about the levels of others' consumption and savings?". The respondent was asked to mark down the level of jealousy from 5 response options, where 1 corresponded to "not jealous at all" and 5 denoted "very jealous". The second question concerned the respondent's definition of their reference group. They were asked to choose one category, from those applicable to them, as their reference group among (i) relatives,

\footnotetext{
${ }^{6}$ Hence, the effective response rate was 30.0 percent for our study. The average response rate for surveys of this kind conducted by the company is reportedly around 35 percent.
} 
(ii) neighbors, (iii) friends, (iv) friends from school, (v) colleagues, and (vi) others. Out of the entire sample, only 43 respondents (4.1 percent) stated that they do not have a reference group and do not compare themselves with others. After answering these two questions, the respondents were considered ready for the following situation choice tasks of social comparison.

Our research strategy was to elicit respondents' preference toward social comparison through choice experiments (stated preference method). Among some of the previous theoretical studies on preference externalities, such as Futagami and Shibata [1998], it was assumed that people care about relative amount of wealth, that is, a stock variable. However, in our survey, in order to avoid the complexities involved in inter-temporal economic decision making, we concentrate on the intra-temporal aspect of social comparison. That is, we consider the allocation of consumption and saving out of certain amount of income for a given period, but do not consider financial or real stock as a device of social comparison. $^{7}$ Note that we did not specify a time span because doing so may remove reality from the choice task for some subjects. Instead, given the levels of attributes, the respondents could adjust the time span for consumption and saving in accordance with their real lives. One more crucial matter in the choice experiment is how to define an appropriate reference person in the socio-economic choice experiment; the possibilities, including the average person in society, colleagues, persons defined by the Leyden school definition, family, neighbors, and so forth, are endless. Nevertheless, our preferred specification here is that the reference point is given by "some representative person in society", a definition which is akin to that used in previous theoretical studies. The situation choice tasks employed in this study are as follows.

Question: Imagine that for a given period of time you can make consumption and savings of certain amounts. In the following figures, pairs of your consumption and saving as well as those of "some representative person in so-

\footnotetext{
${ }^{7}$ Using the perpetual inventory method, we may be able to infer a steady state level of wealth in a dynamic setting from our intra-temporal decision problem.
} 
ciety" are presented. Imagine that each set on your consumption-saving profile and the other's consumption-saving profile regulates society's socio-economic situations. Which of situation 1 and 2 do you prefer?

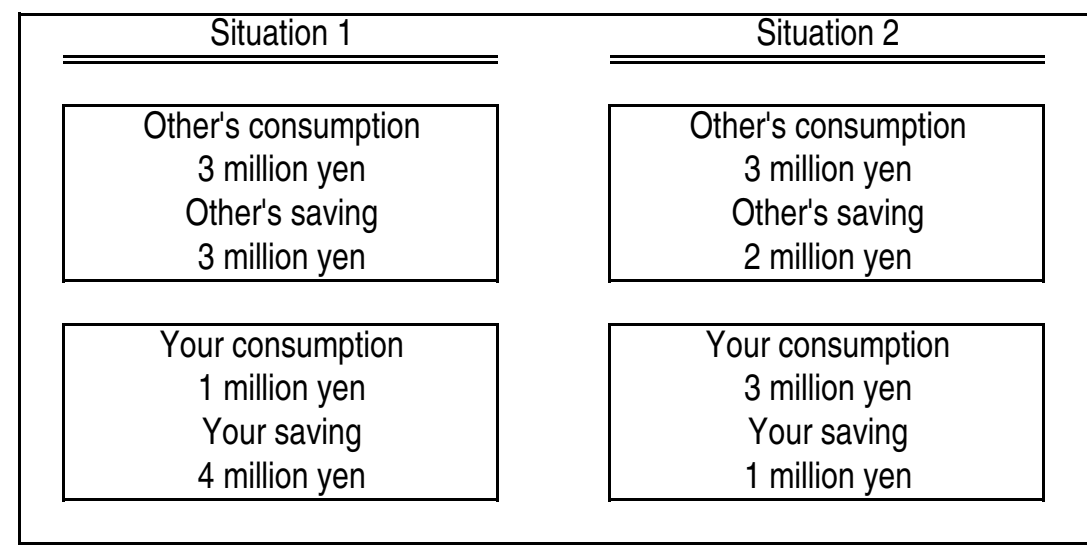

Ans. (1) Situaion 1 (2) Situation 2 (3) don't know, cannot choose

Hence, in this choice experiment we assume that there are four attributes for an alternative. Respondents receive information on these four dimensions of the choices: own consumption, own saving, other's consumption, and other's saving. Respondents repeat eight situation choices, which are defined along these four dimensions. So, in the case of the example given above, if a subject is concerned only with his own consumptionsaving levels and if he is inclined to saving, he will choose Situation 1. However, if the subject feels jealous of the other's consumption and/or saving, he may choose Situation 2 at the expense of his own economic activity in order to turn away from the other's higher level of saving in Situation 1. If he has an altruistic preference (admiration), he may choose Situation 1 even when he wants to make consumption more in Situation 2. After some pretests, we determined the levels of these attributes and the survey included the following situation variations - JPY 1 million, JPY 2 million, JPY 3 million, or JPY 4 million for each dimension. The choice sets were selected via orthogonal design and 16 situation choices out of a total of 256 potential variations were used in the survey. ${ }^{8}$

\footnotetext{
${ }^{8}$ We used SPSS ver 15.0 for orthogonal design and STATA ver 10.1 for the rest of the empirical analyses, together with Hole's STATA modules for mixed logit model estimation (Hole [2007]).
} 
Similarly to Viscusi et al. [2008], the choice design was paired so as to balance the utility of each alternative (Huber and Zwerina [1996]). Finally, we avoided dominant options or easy choices. With all these devices, we could efficiently obtain parameter estimates. We removed observations in which the no-choice option (3) was selected in the choice tasks from our study sample, leaving us with 6,872 observations out of the total $8,344(82.3$ percent).

\subsection{Testing Social Preference with Happiness Regressions}

While our main focus is on choice experiments for measuring the shape of utility function, we can investigate if our study sample has social preference in general by performing happiness regressions. The survey asked each respondent to provide information on his own level of pecuniary satisfaction in life by selecting from 5 response options, where 1 corresponded to "least satisfied" and 5 denoted "most satisfied". The survey also asked that, from a list of 15 categories, workers mark down their own level of wage and subjective perception of reference wage, where the reference group was defined in the Leyden school fashion. ${ }^{9}$ In the analysis that follows, we measure individual income as the mid-point in each of the 13 intermediate categories, and use ad hoc values close to the minimum and maximum wage levels for the two extremes. Thus, respondents who reported categories $1,2, \ldots, 15$ as their annual income level, were assigned an annual income of $0 ; 0.5$; . . . ; 22.5 million yen, respectively. We also collected information about financial assets using 12 response options. The assigned values for financial assets in the regressions are determined as explained in Table 2. Alternative choices do not alter the main results. ${ }^{10}$ Figure 1 shows the averages of reported happiness and reference income category across own income categories. As can be seen, those with a higher annual income tend to report a higher level of happiness, while they expect a higher level of reference income. Therefore,

\footnotetext{
${ }^{9}$ The question concerning the reference wage was phrased as "What do you think the average annual total wage is of those who are your age, gender, and educational attainment?"

${ }^{10}$ Table 2 shows the distribution of income and financial assets among subjects. We provided Category 16 for annual income and Category 13 for financial assets for those who do not want to provide such information.
} 
it is plausible that richer people feel happier (Alesina et al. [2004]). In addition, richer people will expect a higher reference income because the reference group in the survey is defined as a group with similar individual characteristics, which covers income level.

Since less satisfied people may tend to report a higher level of reference wage, there might be endogeneity between pecuniary satisfaction in life and the level of reported reference wage. In order to control for this potential endogeneity, we use the information on pecuniary jealousy which is described in section 3. In this paper, we take this jealousy measure to reflect pessimism among subjects, which can be used to control the bias for pessimistic people (de la Garza et al. [2009]). Figure 2 illustrates the averages of jealousy and reference income category across the level of satisfaction. As shown, those with a higher level of satisfaction tend to report a lower level of pecuniary jealousy. On the other hand, they also report a higher level of reference income. We need to move to multivariate analysis in order to see how the proxy of reference income - the measure of social comparison - affects satisfaction. The data set also allows us to control for individual demographic characteristics, which include gender, region, occupation, educational attainment, number of children, and marital status. ${ }^{11}$

Table 3 shows the results of baseline regressions where individual demographic characteristics are not controlled. In the first column, we see that log of own income affects pecuniary satisfaction positively and significantly. The sign of log of reference income, however, is negative, which means that people tend to have not altruism but rivalry, although this does not reach significance. In the second column where we add financial assets into the set of independent variables, the effect of social comparison becomes significant at the 10 percent level. When we add our measure of jealousy in column (4), we find that jealousy affects satisfaction negatively. ${ }^{12}$ In column (6) where we add all the baseline regressors, we find that all of them are estimated correctly and are significant except for own income. In Table 4, we investigate the effects of introducing other indi-

\footnotetext{
${ }^{11}$ In the happiness regressions presented below, from the total of 1,043 observations, 177 were lost due to insufficient information on financial assets or annual income level, leaving us with 843 .

${ }^{12}$ The effect is found to be robust across specifications.
} 
vidual demographic characteristics as regressors so as to determine whether the results in Table 3 are robust. The results show that, although in some specifications significance is not reached, our study sample has social preference as a form of rivalry, given that the reference income terms affect satisfaction negatively. ${ }^{13}$ With this observation, we expect that in the following choice experiments we will obtain negative externalities in utility function.

\section{Basic results from a random utility model}

\subsection{Random utility model}

Here we describe our theoretical foundation of the concept of conjoint analysis. Individuals derive utility from their own consumption of a homogenous good $c$ and own saving s. In addition, they may be affected by the levels of consumption $C$ and saving $S$ of their representative person in society. Since each individual cannot choose the levels of consumption and saving made by the representative person, the other's consumption and saving are considered as regulating consumption externality and saving externality, respectively. In this case, the utility function is generally given by

$$
U=U(c, s, C, S)
$$

where $U$ represents the utility function. From textbook assumptions, we suppose that subjects value attributes $c$ and $s$ positively. On the other hand, the representative person's consumption and saving can be valued positively or negatively. Hence, an increase in the level of consumption/saving by the representative person in society may raise or lower the level of the other's welfare. Following the literature, a negative externality is characterized as jealousy, while a positive one is characterized as admiration. We address the following

\footnotetext{
${ }^{13}$ We would attribute non-significance in our regressions to the small number of samples.
} 
utility function in which each component is described by an exponential form as

$$
U=c^{\alpha} s^{\beta} C^{\chi} S^{\psi}
$$

where $\alpha, \beta, \chi$ and $\psi$ are parameters. ${ }^{14}$ We presume that $\alpha$ and $\beta$ are positive. We do not impose restrictions on $\chi$ and $\psi$ a priori, because they are regulated by social norm. If their signs are positive, then the social norm of social comparison will be of admiration; if they are negative, society has a social norm of jealousy.

To analyze the conjoint decisions, we use a random utility model framework. Let $i$ denote alternative $i$, and $n$ denote respondent $n$. Then, in order to bring the theoretical framework to the data, we take the logarithms of both sides in Equation 2 to obtain

$$
\ln U_{n i}=\alpha \ln c_{n i}+\beta \ln s_{n i}+\chi \ln C_{n i}+\psi \ln S_{n i}
$$

The above expression can be used for estimating parameters via a random utility model together with an error term $\epsilon_{n}$. The probability $p_{n i}$ that respondent $n$ prefers alternative $i$ to alternative $j$ is given by

$$
\begin{aligned}
p_{n i} & =\operatorname{Prob}\left(\alpha \ln c_{n i}+\beta \ln s_{n i}+\chi \ln C_{n i}+\psi \ln S_{n i}+\epsilon_{n i}\right. \\
& \left.>\alpha \ln c_{n j}+\beta \ln s_{n j}+\chi \ln C_{n j}+\psi \ln S_{n j}+\epsilon_{n j}\right), \text { for all } j \neq i .
\end{aligned}
$$

When $\epsilon_{n}$ is distributed following independent and identical distribution of extreme value type 1 (IIDEV1), we obtain a conditional logit model (McFadden [1974]). Logit models estimate the parameters in Equation 4 using the maximized likelihood method with data from choice experiments. Here, it should be remembered that estimated variables are divided by the scale parameter $\sigma$, which is unknown to researchers (Train [2003], p41). Namely,

\footnotetext{
${ }^{14}$ It is also possible that we address the constant relative risk aversion (CRRA) type utility function. Implications obtained below remain unchanged.
} 
[e]ach of the coefficients is scaled by $1 / \sigma$. The parameter $\sigma$ is called the scale parameter, because it scales the coefficients to reflect the variance of the unobserved portion of utility. (Train [2003])

We cannot obtain the "true" magnitude of the parameters in Equation 3 without additional restriction, since the estimated version of Equation 3 then should be expressed as

$$
\ln U_{n i}=\frac{\alpha^{*}}{\sigma} \ln c_{n i}+\frac{\beta^{*}}{\sigma} \ln s_{n i}+\frac{\chi^{*}}{\sigma} \ln C_{n i}+\frac{\psi^{*}}{\sigma} \ln S_{n i}+\epsilon_{n},
$$

where the original parameters are obtained as $\alpha=\frac{\alpha^{*}}{\sigma}, \beta=\frac{\beta^{*}}{\sigma}, \chi=\frac{\chi^{*}}{\sigma}$, and $\psi=\frac{\psi^{*}}{\sigma}$. Quoting Train [2003] again,

for interpretation it is useful to recognize that these estimated parameters are actually estimates of the original coefficients $[\alpha, \beta, \chi$, and $\psi]$ divided by the scale parameter $\sigma$. The coefficients that are estimated indicate the effect of each observed variable relative to the variance of the unobserved factors. A larger variance in unobserved factors leads to smaller coefficients, even if the observed factors have the same effect on utility (i.e., higher $\sigma$ means lower $[\alpha$, $\beta, \chi$, and $\psi]$ even if $\left[\alpha^{*}, \beta^{*}, \chi^{*}\right.$, and $\psi^{*}$ are $]$ the same).

Previous studies, such as Ida and Goto [2009], tended to assume that $\sigma=1$ so that estimated variables are interpretable without knowledge of $\sigma{ }^{15}$ Such a normalization is innocuous because Train [2003] showed that the overall scale of utility is irrelevant. ${ }^{16}$ In this study, we impose another restriction on the scale parameter $\sigma$ to obtain our preferred "true" set of parameters.

\footnotetext{
${ }^{15}$ Ida and Goto [2009] called $\lambda$ a scale parameter, which is defined as $\lambda=\frac{\pi}{\sqrt{6} \sigma}$. See, for this point, Louviere, Hensher, and Swait [2000].

${ }^{16}$ If we wish to know the difference of variance between the sub-groups in the study sample, the heteroscedastic logit model can be used. It is interesting to discuss the accuracy of decision making in choice experiments through observing the heterogeneity of error variance among sub-groups (de Palma, Myers, and Papageorgiou [1994]). For further analysis of the heterogeneity of the error term in our research context, see our accompanying paper.
} 


\subsection{Results from conditional logit model}

In the conditional logit model, it is assumed that the IIA assumption holds: random components of each alternative are not correlated. We also assume that the random components within each subject are not correlated. Later, we proceed to the mixed logit model where these assumptions are relaxed and the distributions of parameters across subjects are allowed.

Results from the conditional logit model are shown in Table 5. In the left panel, we see that both self consumption and self saving affect utility positively and significantly, as is expected. On the other hand, the effects of other's consumption and saving are estimated to be negative. These effects are significant at the 1 percent level. At this point, we can provide two of our baseline results from the choice experiments as follows. First, the fact that self consumption and self saving affect utility positively will validate our structure of the survey because the results from the choice experiments conform to textbook economic assumptions. Next, we can suggest that externalities in the utility function are regulated as negatives. Hence, the dominating social norm of pecuniary comparison in the Japanese economy will not be of admiration but of jealousy. This finding is in line with our previous results from happiness regressions.

As described above, estimates in Table 5 do not provide the "true" magnitude for the parameter set because they are divided by unknown $\sigma$. To obtain a clearer implication on the shape of utility function, we impose our preferred normalizing assumption that the utility function is homogenous of degree one with respect to own income, that is, the sum of consumption and saving. From the specification in Equation 5, we obtain our preferred "true" parameter set by dividing the estimates with $0.3766+2.0226=2.3992(=1 / \sigma)$. Thus, our choice experiment specifies the shape of utility function which encompasses negative externalities as

$$
U=c^{0.157} s^{0.843} C^{-0.045} S^{-0.182}
$$

Some further implications can be drawn from Equation 6. First, with respect to self 
allocation of resources, saving plays a more dominant role than consumption. The ratio of elasticity of utility on self consumption to that on self saving is estimated to 0.186. The same pattern can be found with respect to other's consumption and saving. This inclination to saving may derive from the fact that the survey was conducted in the midst of the recent financial recession. The severe market conditions might have induced subjects to refrain from consumption behavior such that they increase saving in readiness for uncertain future economic situations.

Second, we obtain that the welfare loss in a competitive symmetric equilibrium caused by the estimated preference externality is around 2.6 percent, compared to the social optimum. ${ }^{17}$ While this loss of 2.6 percent compared to the optimum is that resulting from a one-shot economic decision, we may be able to compare our figure with the results from dynamic models such as the monetary models of Lucas [2000] and the sticky price model of Amano, Moran, Murchison, and Rennison [2009] if we refer to the steady state implications of these dynamic models. We argue that the intensity of market inefficiency from social preference is comparable to that from inflation and price rigidity, and call for more attention from macroeconomic studies along this line. Also, here we can refer to theoretical studies on consumption externality such as Dupor and Liu [2003], Liu and Turnovsky [2005], Chen and Hsu [2007], Nakamoto [2009a], and Nakamoto [2009b]. From Equation 6,we obtain that the sign of the cross-derivative between self-consumption and other's consumption is negative, indicating a running-away-from-the-Joneses effect. In other words, individuals are anti-conformists who dislike being similar to others. ${ }^{18} 19$

The third implication is that the effect of self-budget will dominate that of the other's budget. This point can be confirmed more clearly by considering a utility function which

\footnotetext{
${ }^{17}$ See Appendix 1 for the derivation.

${ }^{18}$ Yamada [2008] investigated a macroeconomic model with conspicuous consumption and showed that if the social norm is anti-conformity, the development process of the economy is monotonic.

${ }^{19}$ We can confirm the concavity of the utility function in Equation 6 . In the symmetric equilibrium, the marginal utility of consumption and saving is positive and increasing in respective arguments. The utility function has the characteristic of joint concavity with consumption and saving (i.e., $\frac{\partial^{2} U}{\partial C \partial C} \frac{\partial^{2} U}{\partial S \partial S}>$ $\left.\frac{\partial^{2} U}{\partial C \partial S}\right)$. This property can be viewed as helpful because the interior solution is guaranteed when the maximization problem in the symmetric equilibrium is considered.
} 
depends on own income $i$ and other's income $I$ as

$$
U=U(i, I)
$$

In the survey, the level of own income can be naturally obtained as the sum of self consumption and self saving. From the right panel of Table 5 in which the result from Equation 7 is illustrated, we see that the point estimate on self-income is much greater than that of other's income. More importantly, from the 95 percent confidence intervals of these two variables, we can confirm that the absolute value of the lower bound for self-income is greater than that for other's income. Thus, we suggest that raising the incomes of all by the same amount will increase the happiness of all. Put another way, this finding contradicts the famous Easterlin paradox (Easterlin [1974], Easterlin [1995]) and favors the money-buys-happiness hypothesis (Alesina et al. [2004]). The novelty of our paper is that we derived the implication by estimating the shape of utility function directly with the choice experiment, not from happiness regressions. ${ }^{20}$

The specification of Equation 7 is also useful for estimating CRRA utility function as appeared in Liu and Turnovsky [2005]. We address a CRRA type utility function of the form:

$$
U=\frac{1}{1-\gamma}\left(i I^{\kappa}\right)^{1-\gamma}
$$

By applying estimates in Table 5, the utility function is specified as

$$
U=\frac{1}{1-0.2739}\left(i I^{-0.3160}\right)^{1-0.2739}
$$

where the scale parameter is obtained as $1 / \sigma=1 /(1-0.2739)$.

\footnotetext{
${ }^{20}$ In addition to happiness studies with micro data, some studies have provided evidence of "money buys happiness". Examples include Alesina et al. [2004] and de la Garza et al. [2009]. However, the seminal paper in the literature, Clark and Oswald [1996], showed otherwise. See Clark et al. [2008] for an excellent review.
} 


\section{Heterogeneity of preference parameters across in- dividual characteristics}

\subsection{Results from mixed logit model}

Table 6 shows the results from a mixed logit model in which distributions of parameters are allowed. In other words, in the mixed logit model, we can observe heterogeneity of preference among respondents. Although we assume that the error term is independently and identically distributed as in the conditional logit model, the mixed logit model allows the discrete choice model to apply in the non IIA situation. Estimates in the table generally show that our previous results obtained with the conditional logit model are robust. Attributes for self-budget affect utility positively, whereas the externalities are picked up as negatives.

Table 6 also suggests that the means of estimates from the mixed logit model are not very different from the point estimates from the conditional logit model. While this finding validates the robustness of previous findings, the standard deviations estimated may require some attention. In particular, the standard deviation for the Self Consumption term looks large compared to the mean and is significant. The standard deviation for $\chi$ is not significant whereas that for $\psi$ is found to be significant at the one percent level. This outcome could imply that heterogeneity in social preference parameters is an important issue.

The right panel of Table 6 provides another interesting implication. It shows that the average estimate of the Other's Income term is negative. The associated standard deviation is large compared to the mean, and more importantly it is significant. This implies that there is large heterogeneity in the parameter for preference externality. Looking at the distribution of the preference parameter, we can estimate that 64.4 percent of our study sample has negative externality (jealousy) regarding other's income and that the remaining 35.6 percent have positive preference externality (admiration). This evidence 
serves to support the strategies adopted in theoretical studies on preference externality such as Liu and Turnovsky [2005] and Nakamoto [2009b] which deal with both jealousy and admiration. A caveat here is that economists may do better to think about to what extent jealousy or admiration is pervasive in a macro-economy, rather than to think about an economy where preference externality is characterized only by a negative or a positive one. In that sense, the research agenda of Garcia-Penalosa and Turnovsky [2008] which considers the heterogeneity of preference parameters is more promising.

The abovementioned findings suggest that heterogeneity of preference parameter exists, and ask for further analyses on the determinants of preference structure. In the next section, we provide the results from the conditional logit model with dummy interactions in order to investigate if differences in individual characteristics lead to differences in parameters of utility function.

\subsection{Results from conditional logit model with dummy interac- tions}

In the literature of behavioral economics, it is well-recognized that demographic differences lead to substantial differences in deep parameters such as the time discount rate and the rate of risk aversion. Ida and Goto [2009] showed that smokers are endowed with a higher value of time discounting and a lower value of risk aversion than nonsmokers. Viscusi et al. [2008] showed that eco-conscious individuals have a lower rate of time discounting than those who are not eco-friendly, but that they exhibit a hyperbolic discounting pattern. Small, Winston, and Yan [2005] applied the framework of a mixed logit model to investigate the distribution of commuters' preferences for speedy and reliable highway travel, finding that there was substantial heterogeneity in motorists' values of travel time and reliability, suggesting road pricing policies should be designed to cater to various preferences. Hole [2008] investigated preferences of patients over general practitioner appointments using standard logit, mixed and latent class logit 
models. He showed that there was significant preference heterogeneity for all the attributes in the experiment. Using micro-consumption data, Mastrobuoni and Weinberg [2009] found that those with financial assets of less than 5,000 US dollars tend to behave as hyperbolic consumers, while those with more than that amount can smooth their intra-monthly pattern of consumption. In addition, from the viewpoint of neuroscience, Tanaka, Doya, Okada, Ueda, Okamoto, and Yamawaki [2004] and McClure, Laibson, Loewenstein, and [2004] showed that separate parts of the human brain make short-run and long-run decisions. Thus, if individual characteristics such as gender or age determine which decision making part of the brain becomes more active, they may explain differences in the time discount rate by those organic variables. In the following analyses, we investigate if differences in individual characteristics have consequences on parameter difference of social preference. We consider four acquired individual characteristics as well as two organic factors as potential sources of parameter heterogeneity.

As a starting point for thinking about heterogeneity issues, it is highly plausible that difference in income level or amount of financial assets brings about differences in externality parameters in the utility function. Considering that the rich can make more of consumption and saving than the poor, this would lead us to expect that the poor may feel jealousy about other's consumption, and thus exhibit a higher level of negative consumption/saving externality. On the other hand, taking a different line, the rich could be considered rich because they have innate characteristics of chasing more wealth which is derived by negative pecuniary externality. Keynes [1971], Zou [1994] and Bakshi and Chen [1996] all suggested that rat races to accumulate wealth among the super rich can be explained by the keeping-up-with-the-Joneses effect (negative externality associated with asset). As a benchmark, we consider those individuals in an annual income category higher than 8 as the Income Rich group and those with a financial asset category higher than 2 as the Financial Asset Rich group. They account for 14.0 percent and 34.5 percent of the full sample, respectively.

Another consideration is educational attainment because education itself can work 
as a reputation device and reputation will work as an externality in consumption-saving decisions. Our conjecture is that individuals with higher academic achievements will be endowed with a higher reputation in society, which makes them more conspicuous. If it is true, those with higher educational achievements will have stronger negative externality in consumption and saving. In this study, those with under-graduate or graduate degrees are classified into the High Education group. They account for 41.0 percent of the full sample.

In addition, we consider that the difference in the location of dwelling may cause heterogeneity in the individuals' preferences. For instance, in Japan, it is said that the relationship with neighbors is closer in rural areas than in urban areas. Hence, people in urban areas may be generally less concerned about other's consumption and saving, and externalities in their utility function may become weaker. We therefore consider a sub-group of those from Tokyo, Osaka, or Nagoya — the Urban group — which consists of 26.9 percent of our study sample.

Related to the organic variables are the two variables of age and gender. We consider them because of findings in neuroscience. Our hypothesis regarding age is as follows. Since the average life expectancy of the old is in general shorter than that of the young, we assume here that, compared to the young, the old use a higher time discount rate, thus becoming myopic. This may lead to jealousy of other's consumption among older people, which results in greater consumption negative externality amongst the elderly. Along the same lines, we assume that the young are more concerned about other's saving because saving is activity carried out over an uncertain long future. As a benchmark, we use the Young group consisting of those under the age of 40. They account for 40.6 percent of our study sample. Finally, regarding gender, we have no conjectures a priori, but Veblen [1899] provides us with a presumption here. He writes that [f]rom archaic times down through all the length of the patriarchal regime it has been the office of the women to prepare and administer these luxuries, and it has been the perquisite of the men of gentle birth and breeding to consume them .... This invidious traditional distinction has not 
last its force even among the more advanced peoples of today (p.70). Today's society is much more advanced than in Veblen's time so such a traditional distinction would have vanished in general, but still, the gender difference is an interesting point to be pursued in investigating heterogeneity of preferences. Data from women account for 44.8 percent of our study sample.

Focusing on differences in these demographic variables, we add interactions with various dummies into the original four attributes for estimates based on the full sample. We lost 1,035 observations from the choice experiment because some subjects chose not to provide information on financial assets or annual income level, leaving us with 5,847 observations.

Table 7 reports the results with various dummy interactions. From the first column, we can see that those with a higher income feel more jealous about consumption than those with a lower income. Also, the significance of other's consumption is lost after including the dummy interactions. It seems that consumption externality was driven by preference in the high income group. On the other hand, negative externality related to saving remained unchanged, and the dummy interaction term for other's saving is not significant.

Given the stronger negative consumption externality among individuals with a high income, it is somewhat surprising that the difference in the amount of financial assets does not lead to parameter heterogeneity, as is shown in the second column of Table 7. As we will show later, this finding is quite robust against changes in threshold level for the Asset Rich group. Note also that the robust standard error of the estimate for other's consumption is large, despite still being significant at the 10 percent level, after including the dummy interactions.

Regarding the other two acquired individual characteristics, educational attainment and place of dwelling, we see that the dummy interaction terms with preference externalities are not significant. The estimates for the original four attributes are not very different from those in the baseline conditional logit model (Table 5). Hence, we see that 
the heterogeneity in educational attainments and housing place do not affect preference parameter heterogeneity.

Much more interesting findings are shown in the last two columns of Table 7. Although the effects are seen to have marginal significance, younger people have weaker negative consumption externality and stronger negative saving externality than the elderly. Put differently, the elderly have stronger negative consumption externality and weaker negative saving externality. These effects may have something to do with life expectancy and we refer to the literature of evolutionary economics that considers evolution and adaption of preference structure. Studies in evolutionary economics have recently examined how people form an optimal shape of happiness over time. ${ }^{21}$ Our findings may suggest that preference structure is actually chosen in an optimal fashion over time: facing a shorter life expectancy, the elderly shift negative externality in preference from that related to saving to that associated with consumption. Because saving will play a minor role in lives of the elderly, this shift of preference structure will mitigate the welfare loss associated with consumption. Finally, we see that females feel more jealous with respect to both consumption and saving than males. Well after the time of Veblen, our data collected in March 2009 shows that the socio-economic situation has changed.

To sum up, we see that income difference, age, and gender result in parameter heterogeneity associated with social preference. Thus, we can confirm that heterogeneity plays a role in determining the parameters just as previous behavioral economics studies have found in other fields. In our case, however, these differences are picked up weakly, and therefore we proceed to robustness checks.

In Table 8, we consider all the variables which potentially cause parameter heterogeneity in each equation. Dummy interactions are taken for the original four attributes, but the results are shown only for preference externality terms. Column (1) shows the baseline case, where threshold levels of financial assets, annual income, and age are given

\footnotetext{
${ }^{21}$ See, for example, Robson [1996], Robson [2001], Rayo and Becker [2007a], Rayo and Becker [2007b], and Netzer [2009].
} 
as category 2 , category 8 , and 40, respectively. From column (1), we see that the effects of Income Rich on other's consumption, of Young on other's saving, and of Female on other's consumption and saving are found to remain the same as before. On the other hand, the effect of Income Rich on other's saving becomes significant, and the effect of Young on other's saving loses its significance. This result is, in general, supportive of previous findings. Columns (2) and (3) are threshold changes in the Financial Asset Rich group in categories 3 and 4, respectively. Columns (4), (5), and (6) are threshold changes in the Income Rich group in categories 7, 9, and 10, respectively. Finally, in columns (7), (8), and (9), we changed the threshold age for the Young group to 30, 35, and 45, respectively. Through columns (2) - (9), variables other than the variable for the robustness checks are kept as the baseline value. The results show that our previous findings are in general robust to the threshold levels chosen. We therefore conclude that the individual characteristics that bring about heterogeneity in social preference parameters are income level, age, and gender. Asset level, educational attainment, and place of dwelling are not factors to be pursued.

\section{Conclusions}

In the literature of behavioral economics, important parameters have been estimated via experiments, and policy implications derived from theoretical studies that address these parameters have attained a richness and more practical adaptation. Although the social preference effect is well recognized and although there are a number of happiness studies that support the view of social preference, direct information on the shape of utility function with social preference was lacking. In this paper, we have introduced a new framework to the literature of social preference, allowing us to obtain findings which are more directly applicable to theoretical studies of social preference than those reported in the literature of happiness studies.

Here, we specified the shape of utility function with social preference with the condi- 
tional logit and mixed logit models. Our major findings can be summarized as follows. First, preference externality is characterized by jealousy rather than admiration among Japanese respondents. Second, the welfare loss in a competitive symmetric equilibrium caused by the preference externality is around 2.6 percent, compared to the social optimum. Third, considering demographic differences, heterogeneity in social preference parameters was shown to be driven by differences in income level, age, and gender.

Possible directions of future research include, first, a consideration of inter-temporal choice tasks in order to investigate utility functions which depend on a stock variable of wealth, since in the theoretical literature of social preference, preference externalities are often considered with wealth externality. Second, using heteroscedastic logit models, we can investigate differences in scale parameters across sub-groups of different individual characteristics. Since the scale parameters are inversely proportional to the error variances in logit models, if there are significant differences in them, it implies that different study groups exhibit different levels of comprehension about choice experiments of the kind we addressed here. Third, we found from the mixed logit model analysis that around one third of the respondents are endowed with the social preference of admiration, while the Japanese socio-economy is, on average, characterized by jealousy. These findings in regard to jealousy and admiration should be validated and investigated by macroeconomic studies on preference externality. A suggestion from these findings is that researchers should think about what types of individual characteristics are related to admiration. We can investigate this point using Bayesian inverse formula following Ida and Goto [2009]. These last two topics are investigated in our accompanying papers. 


\section{Appendices}

\subsection{Appendix 1}

In this appendix, following Liu and Turnovsky [2005], we illustrate the effects of preference externalities on individuals' decisions in order to stimulate the reader's intuition. An individual optimally selects the levels of own consumption and own saving to maximize the utility (1) given own level of income $i$. Thus, his budget constraint is given by $i=c+s$. Since the marginal rate of substitution between consumption and saving is given by $-\frac{d s}{d c}=\frac{U_{c}}{U_{s}}$ in (1), the maximizing condition is

$$
-\frac{d s}{d c}=\frac{U_{c}}{U_{s}}=1
$$

where the relative price between consumption and saving is unity. Looking at Figure 3, we can confirm that at the private maximizing point, the solid curve and the budget constraint intersect. It should be remembered that the individual does not take externalities from other's consumption and saving into consideration when private levels of consumption and saving are chosen. Next, we consider the social planner who chooses socially optimal allocations of consumption and saving, taking account of the effects of preference externalities. Variables with tilde denote social optimal levels of consumption and saving chosen by the planner. In this case, the optimal maximizing-condition is given as

$$
-\frac{d s}{d c}=\frac{\tilde{U}_{c}+\tilde{U}_{C}}{\tilde{U}_{s}+\tilde{U}_{S}}=1
$$

where preference externalities are taken into account. For simplicity, here we assume that the form of utility functions is homothetic, thereby obtaining $\tilde{U}_{C}=\chi \tilde{U}_{c}$ and $U_{S}=\psi U_{s}$, where $\chi$ and $\psi$ are parameters of what. The negative sign of $\chi(\psi)$ indicates jealousy externality about reference consumption (saving). If they are positive, admiration is 
observed. Then, Equation (8b) can be rewritten as

$$
-\frac{d s}{d c}=\frac{(1+\chi) U_{c}}{(1+\psi) U_{s}}=1
$$

To focus on the impacts of consumption externalities on the individual's decision, we assume that there does not exist the saving externality $\psi=0$. In this case, from (8c), we can obtain $(1+\chi) U_{c}=U_{s}$. Suppose that subjects feel jealous about reference consumption (i.e., $\chi<0$ ). In this case, $U_{c}>U_{s}$. Figure 3 depicts this case, showing that the level of consumption privately chosen is greater than the socially optimal level. Conversely, when individuals feel admiration, the relationship is reversed. It is easy to see that we can apply the same logic to the effect of saving externalities.

From our estimates of the parameters given in Table 5, we can see how much the externalities in utility function reduce welfare in the competitive equilibrium, compared to the social optimum. From Equation 6 and the budget constraint $i=c+s$, we obtain the private optimal allocations as $c=0.157 i$ and $s=0.843 i$. Assuming a symmetric equilibrium, $i=I$ and $c=C$, the social optimum then can be obtained as $C_{\text {opt }}=0.145 i$

and $S_{\mathrm{opt}}=0.885 i$. Hence, assuming away constant terms in the utility function, we see that the welfare level obtained by the private allocation is reduced by 2.615 percent from the socially optimal level.

\subsection{Appendix 2}

Here we provide some results of the rationality tests. First, one of our questions asked about the reference group that the subjects define. Among 1,043 total respondents, 43 specified that they do not have reference group and do not compare themselves with others. With this information, we divide our entire sample into two groups; those with a reference group and those without a reference group. We divide the entire sample here because the sample with no reference group could affect the structure of the equation more generally (Viscusi et al. [2008]) 
In the experiment, if the subjects understand the socio-economic choice tasks correctly, we will obtain externalities in the estimated utility function for the sub-groups with reference group, while $\xi$ and $\psi$ will not be significantly different from zero for those without reference groups. The number of samples for the first sub-group is still as many as 6,624 while that for the second sub-group is reduced to 224 . Table 9 shows the results. From the left panel, we see that the results obtained above remain unchanged for the sub-group of those with a reference group. However, the right panel shows an intriguing pattern for those without a reference group: as for the coefficients of self budget, self saving is estimated correctly and is significant. On the other hand, other's consumption and saving are estimated to be quite close to zero and do not reach significance. Because of the small number of observations, we do not know how much we can attribute the finding to the rationality of subjects. But still, this finding will at least provide some, albeit weak, evidence that our choice experiments are valid.

Our second rationality test is related to jealousy. We consider two sub-groups, one with higher jealousy (with jealousy $>=4$ ) and the other with lower jealousy (with jealousy $<=3$ ). Because the self-reported intensity of jealousy is a demographic variable, we add interactions of a higher-jealousy dummy, taking value one if jealous $>=4$ otherwise zero, to the original four attributes for estimates based on the entire sample. Table 10 shows the result. As is clearly shown from the second column, the negative externality effect of other's saving gets stronger for the sub-sample with higher jealousy, as is expected. While the externality in other's consumption is indifferent between those with or without higherjealousy, we would attribute this outcome to a general inclination to saving behavior among our subjects.

Following Heberlein, Wilson, Bishop, and Schaeffer [2005], Table 11 shows the result of the scope tests. With respect to Self Saving, estimates indicate that larger saving is related to higher utility. Estimates for dummies related to Self Consumption are not significant and this outcome seems to imply "moral purchase property" regarding Self Consumption (Kahneman and Knetsch [1992]). Nevertheless, we attribute this rather 
disappointing result to the general inclination of subjects to saving. The estimate for Other's Consumption 4 is as expected, while the effects of Other's Consumption 2 and Other's Consumption 3 are not significant. However, the sign is in the right direction.

Finally, the estimates of Other's Saving 3 and Other's Saving 4 seem to be acceptable but the magnitudes of the point estimates are reversed. Note that there is overlap for those estimates in the 95 percent confidence intervals (not shown). The evidence presented above in general supports the validity of our choice experiment.

\section{References}

Andrew B Abel. Asset prices under habit formation and catching up with the joneses. American Economic Review, 80(2):38-42, May 1990.

Alberto Alesina, Rafael Di Tella, and Robert MacCulloch. Inequality and happiness: are europeans and americans different? Journal of Public Economics, 88(9-10):2009-2042, August 2004.

Robert Amano, Kevin Moran, Stephen Murchison, and Andrew Rennison. Trend inflation, wage and price rigidities, and productivity growth. Journal of Monetary Economics, 56(3):353-364, April 2009.

Gurdip S. Bakshi and Zhiwu Chen. The spirit of capitalism and stock-market prices. American Economic Review, 86(1):133-57, March 1996.

Bjorn Bartling, Ernst Fehr, Michel Andre Marechal, and Daniel Schunk. Egalitarianism and competitiveness. American Economic Review, 99(2):93-98, May 2009.

Gary Charness and Matthew Rabin. Understanding social preferences with simple tests. The Quarterly Journal of Economics, 117(3):817-869, August 2002.

Been-Lon Chen and Mei Hsu. Admiration is a source of indeterminacy. Economic Letters, 95:96-103, 2007. 
Andrew E. Clark, Paul Frijters, and Michael A. Shields. Relative income, happiness, and utility: An explanation for the easterlin paradox and other puzzles. Journal of Economic Literature, 46(1):95-144, March 2008.

Andrew E. Clark, Nicolai Kristensen, and Niels Westergard-Nielsen. Economic satisfaction and income rank in small neighbourhoods. Journal of European Economic Association, forthcoming, 2009a.

Andrew E. Clark, Nicolai Kristensen, and Niels Westergard-Nielsen. Job satisfaction and co-worker wages: Status or signal? Economic Journal, 119(536):430-447, March 2009 b.

Andrew E. Clark and Andrew J. Oswald. Satisfaction and comparison income. Journal of Public Economics, 61(3):359-381, September 1996.

Giacomo Corneo and Olivier Jeanne. On relative wealth effects and the optimality of growth. Economics Letters, 54(1):87-92, January 1997.

Giacomo Corneo and Olivier Jeanne. Status, the distribution of wealth, and growth. Scandinavian Journal of Economics, 103(2):283-93, June 2001.

Adrian de la Garza, Giovanni Mastrobuoni, Atsushi Sannabe, and Katsunori Yamada. The relative income hypothesis with and without self-reported reference wages. mimeo, 2009.

Andre de Palma, Gordon M Myers, and Yorgos Y Papageorgiou. Rational choice under an imperfect ability to choose. American Economic Review, 84(3):419-40, June 1994.

Bill Dupor and Wen-Fang Liu. Jealousy and equilibrium overconsumption. American Economic Review, 93(1):423-428, March 2003.

Richard A. Easterlin. Does economic growth improve the human lot? some empirical evidence. In: David, P.A., Reder, M.W. (Eds.), Nations and Households in Economic Growth: Essays in Honour of Moses Abramowitz, 1974. 
Richard A. Easterlin. Will raising the incomes of all increase the happiness of all? Journal of Economic Behavior $\&$ Organization, 27(1):35-47, June 1995.

Ernst Fehr, Helen Bernhard, and Bettina Rockenbach. Egalitarianism in young children. Nature, 454:1079-1083, August 2008.

Ernstand Fehr and Colin F. Camerer. Social neuroeconomics: the neural circuitry of social preferences. Trends in Cognitive Sciences, 11(10):419-427, October 2007.

Ada Ferrer-i Carbonell. Income and well-being: an empirical analysis of the comparison income effect. Journal of Public Economics, 89(5-6):997-1019, June 2005.

Ada Ferrer-i Carbonell and Paul Frijters. How important is methodology for the estimates of the determinants of happiness? Economic Journal, 114(497):641-659, July 2004.

K. Fliessbach, B. Weber, P. Trautner, T. Dohmen, U. Sunde, C. E. Elger, and A. Falk. Social comparison affects reward-related brain activity in the human ventral striatum. Science, 318:11305-308, November 2007.

Bruno S. Frey and Alois Stutzer. Happiness and Economics: How the economy and institutions affect human well-being. Princeton University Press, 2001.

Bruno S. Frey and Alois Stutzer. What can economists learn from happiness research? Journal of Economic Literature, XL:402-435, June 2002.

Koichi Futagami and Akihisa Shibata. Keeping one step ahead of the joneses: Status, the distribution of wealth, and long run growth. Journal of Economic Behavior E Organization, 36(1):109-126, July 1998.

Jordi Gali. Keeping up with the joneses: Consumption externalities, portfolio choice, and asset prices. Journal of Money, Credit and Banking, 26(1):1-8, February 1994. 
Cecilia Garcia-Penalosa and Stephen Turnovsky. Consumption externalities: a representative consumer model when agents are heterogeneous. Economic Theory, 37(3): 439-467, December 2008.

Thomas A. Heberlein, Matthew A. Wilson, Richard C. Bishop, and Nora-Cate Schaeffer. Rethinking the scope test as a criterion for validity in contingent valuation. Journal of Environmental Economics and Management, 50(1):1-22, July 2005.

Arne Risa Hole. Fitting mixed logit models by using maximum simulated likelihood. Stata Journal, 7(3):388-401, 2007.

Arne Risa Hole. Modelling heterogeneity in patients' preferences for the attributes of a general practitioner appointment. Journal of Health Economics, 27(4):1078-1094, 2008.

Joel Huber and Klaus Zwerina. The importance of utility balance in efficient choice designs. Journal of Marketing Research, 33(3):307-317, 1996.

Takanori Ida and Rei Goto. Simultaneous measurement of time and risk preferences. International Economic Review, 50(4):in press, 2009.

K. Jensen, B. Hare, J. Call, and M. Tomasello. What's in it for me? self-regard precludes altruism and spite in chimpanzees. Proc. Biol. Sci., 273:1013-1021, 2006.

K. Jensen and M. Tomasello. Chimpanzees are rational maximizers in an ultimatum game. Science, 318:107-109, 2007.

Daniel Kahneman and Jack L. Knetsch. Valuing public goods: The purchase of moral satisfaction. Journal of Environmental Economics and Management, 22(1):57-70, January 1992.

Daniel Kahneman, Alan B. Krueger, David Schkade, Norbert Schwarz, and Arthur A. Stone. Focusing illusion would you be happier if you were richer? Science, 312:19081910, 2006. 
John M. Keynes. The Economic Consequence of the Peace. St. Martin's Press: London, 1971.

Wen-Fang Liu and Stephen Turnovsky. Consumption externalities, production externalities, and long-run macroeconomic efficiency. Journal of Public Economics, 89(5-6): 1097-1129, June 2005.

J. J. Louviere, D. A. Hensher, and J. D. Swait. Stated Choice Methods. Cambridge University Press (Cambridge), 2000.

Robert E. Lucas. Inflation and welfare. Econometrica, 68(2):247-274, March 2000.

Erzo F. P. Luttmer. Neighbors as negatives: Relative earnings and well-being. The Quarterly Journal of Economics, 120(3):963-1002, August 2005.

Giovanni Mastrobuoni and Matt Weinberg. Heterogeneity in intra-monthly consumption patterns, self-control, and savings at retirement. American Economic Journal: Economic Policy, forthcoming, 2009.

Samuel McClure, David Laibson, George Loewenstein, and Jonathan Cohen. Separate neural systems value immediate and delayed monetary rewards. Science, 306(15):503507, October 2004.

Daniel McFadden. Conditional Logit Analysis of Qualitative Choice Behavior in P. Zarembka (ed.) Frontiers in Econometrics. Academic Press, 1974.

Yasuhiro Nakamoto. Consumption externalities with endogenous time preference. Journal of Economics, 96(1):41-62, January 2009a.

Yasuhiro Nakamoto. Jealousy and underconsumption in a one-sector model with wealth preference. Journal of Economic Dynamics and Control, 33(12):2015-2029, December 2009b. 
Nick Netzer. Evolution of time preferences and attitudes towards risk. American Economic Review, 99(3):937-955, June 2009.

Andrew J. Oswald. Altruism, jealousy and the theory of optimal non-linear taxation. Journal of Public Economics, 20(1):77-87, February 1983.

Luis Rayo and Gary S. Becker. Evolutionary efficiency and happiness. Journal of Political Economy, 115:302-337, 2007a.

Luis Rayo and Gary S. Becker. Habits, peers, and happiness: An evolutionary perspective. American Economic Review, 97(2):487-491, May 2007b.

Arthur J. Robson. A biological basis for expected and non-expected utility. Journal of Economic Theory, 68(2):397-424, February 1996.

Arthur J. Robson. Why would nature give individuals utility functions? Journal of Political Economy, 109(4):900-929, August 2001.

Claudia Senik. When information dominates comparison: Learning from russian subjective panel data. Journal of Public Economics, 88(9-10):2099-2123, August 2004.

J. B. Silk and et al. Chimpanzees are indifferent to the welfare of unrelated group members. Nature, 437:1357-1359, 2005.

Kenneth A. Small, Clifford Winston, and Jia Yan. Uncovering the distribution of motorists' preferences for travel time and reliability. Econometrica, 73(4):1367-1382, 07 2005.

Saori Tanaka, Kenji Doya, Go Okada, Kazutaka Ueda, Yasumasa Okamoto, and Shigeto Yamawaki. Prediction of immediate and future rewards differentially recruits corticobasal ganglia loops. Nature Neuroscience, 7(8):887-893, 2004.

Kenneth Train. Discrete Choice Methods with Simulation. Cambridge University Press, Cambridge, 2003. 
Bernald M. S. van Praag. Ordinal and cardinal utility. Journal of Econometrics, 50: 69-89, 1991.

Thorstein Veblen. The Theory of the Leisure Class. reprinted 195\%. George Allen Unwin, London, 1899.

W. Kip Viscusi, Joel Huber, and Jason Bell. Estimating discount rates for environmental quality from utility-based choice experiments. Journal of Risk and Uncertainty, 37: 199-220, 2008.

Katsunori Yamada. Macroeconomic implications of conspicuous consumption: A sombartian dynamic model. Journal of Economic Behavior \& Organization, 67(1):322-337, July 2008.

Heng-fu Zou. 'the spirit of capitalism' and long-run growth. European Journal of Political Economy, 10(2):279-293, July 1994. 


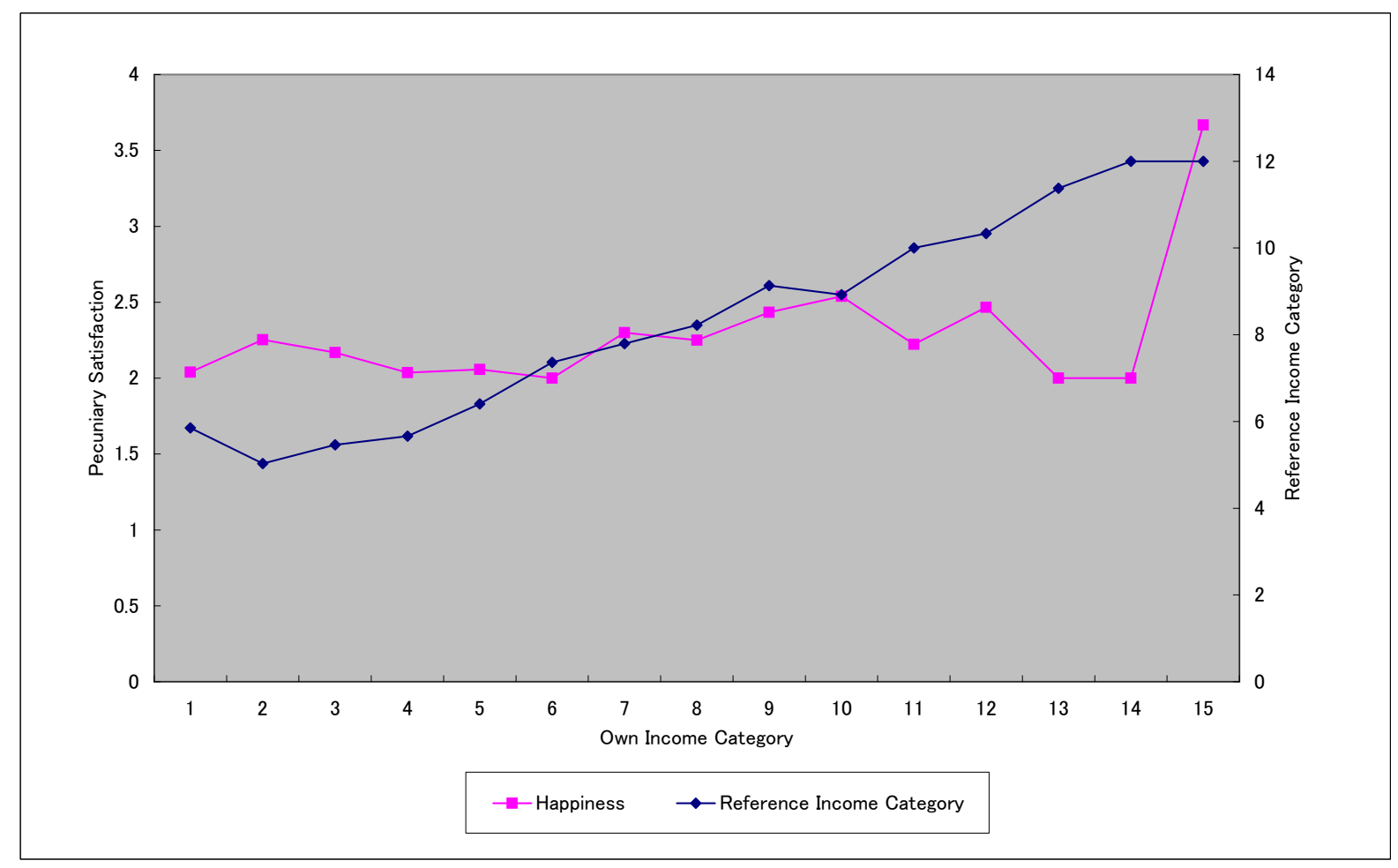

Figure 1: Happiness and Reference Income Level across Own Income Level 


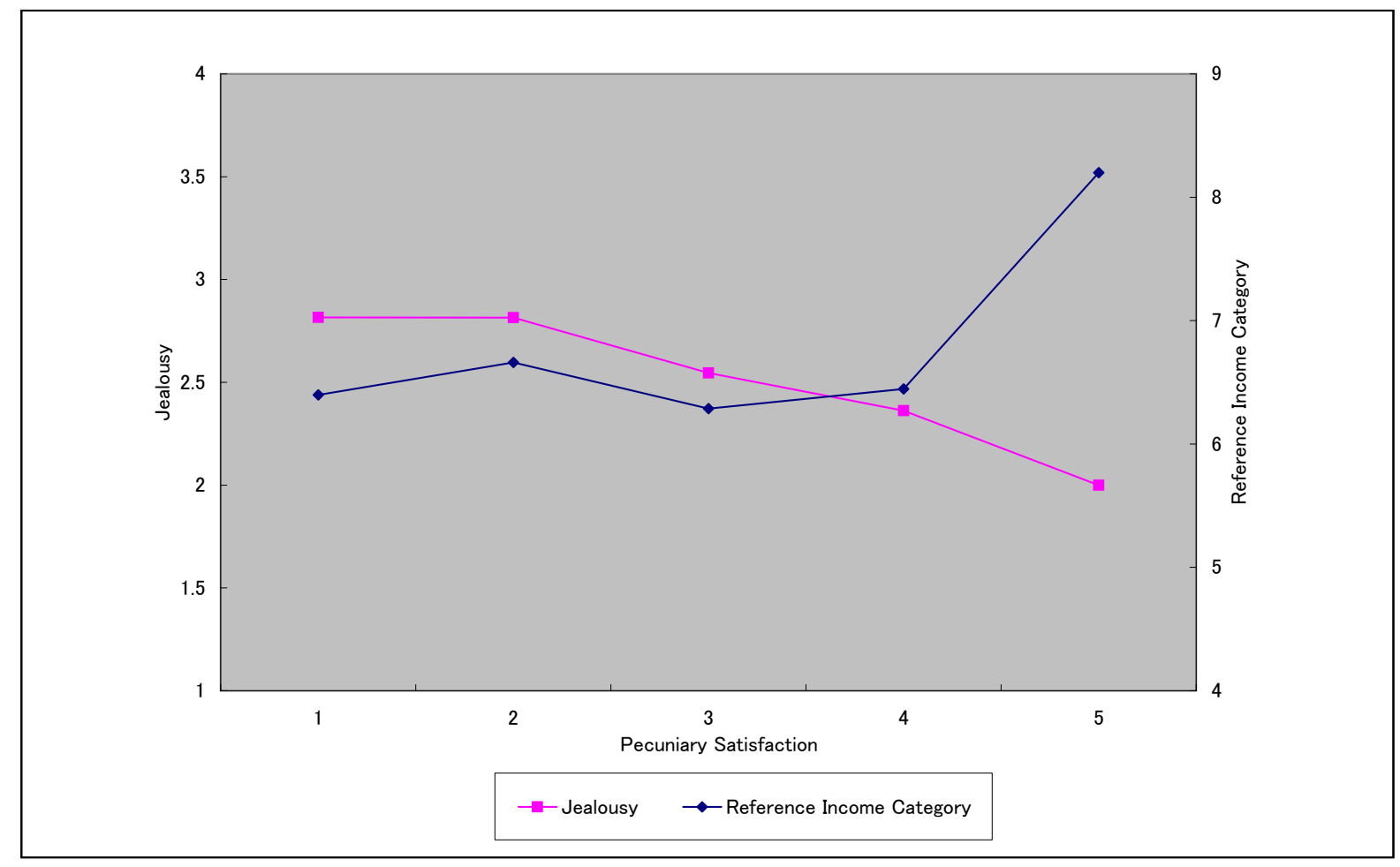

Figure 2: The Level of Jealousy and Reference Income Level across Happiness Level

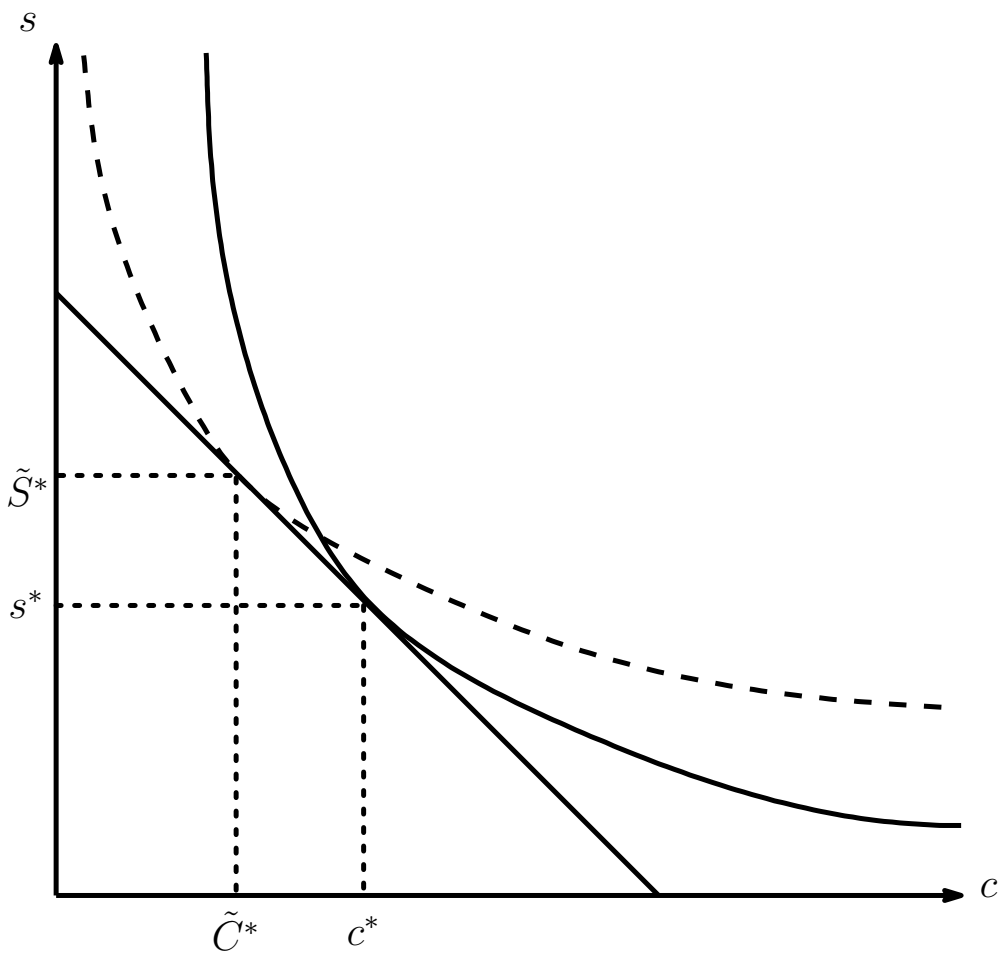

Figure 3: Marginal Rate of Substitution with or without Social Preference 
Table 1: Descriptive Statistics

\begin{tabular}{rrrrrrr}
\hline \hline & \multicolumn{2}{c}{ Whole sample } & \multicolumn{2}{c}{ Male } & \multicolumn{2}{c}{ Female } \\
\hline & Mean & Std. Dev. & Mean & Std. Dev. & Mean & Std. Dev. \\
\hline Variable & & & & & & \\
Female [0,1] & 0.48 & 0.50 & & & & \\
Age in years & 44.86 & 14.62 & 44.69 & 14.33 & 45.04 & 14.95 \\
Middle School [0,1] & 0.03 & 0.18 & 0.03 & 0.18 & 0.03 & 0.17 \\
High School [0,1] & 0.33 & 0.47 & 0.30 & 0.46 & 0.36 & 0.48 \\
College/ Post Grad [0,1] & 0.39 & 0.49 & 0.50 & 0.50 & 0.27 & 0.45 \\
Married [0,1] & 0.65 & 0.48 & 0.65 & 0.48 & 0.66 & 0.48 \\
\hline $\mathrm{N}$ & \multicolumn{1}{c}{1043} & \multicolumn{5}{c}{547} \\
\hline
\end{tabular}




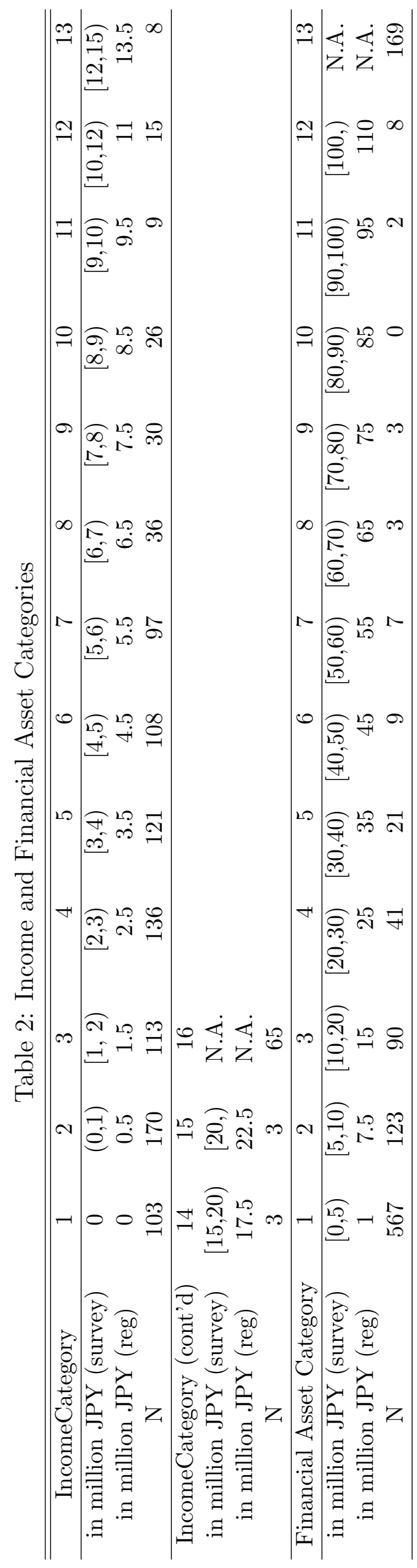


Table 3: Happiness Regressions (PART 1)

\begin{tabular}{rrrrrrr}
\hline \hline & $(1)$ & $(2)$ & $(3)$ & $(4)$ & $(5)$ & $(6)$ \\
\hline Dep var. & Happiness & Happiness & Happiness & Happiness & Happiness & Happiness \\
\hline log income & $0.02^{* * *}$ & 0.01 & & $0.02^{* * *}$ & & 0.01 \\
& $(0.01)$ & $(0.01)$ & & $(0.01)$ & & $(0.01)$ \\
log reference income & -0.02 & $-0.03^{*}$ & -0.03 & -0.02 & -0.03 & $-0.03^{*}$ \\
& $(0.02)$ & $(0.02)$ & $(0.02)$ & $(0.02)$ & $(0.02)$ & $(0.02)$ \\
Jealousy & & & & $-0.13^{* * *}$ & $-0.09^{* *}$ & $-0.09^{* *}$ \\
& & & & $(0.04)$ & $(0.04)$ & $(0.04)$ \\
log financial asset & & $0.34^{* * *}$ & $0.35^{* * *}$ & & $0.34^{* * *}$ & $0.34^{* * *}$ \\
& & $(0.03)$ & $(0.03)$ & & $(0.03)$ & $(0.03)$ \\
\hline Observations & 866 & 866 & 866 & 866 & 866 & 866 \\
\hline
\end{tabular}

Robust standard errors in parentheses

*** $\mathrm{pi}^{\mathrm{i} 0.01,}{ }^{* *} \mathrm{pi} 0.05,{ }^{*} \mathrm{p} \mathrm{i} 0.1$ 


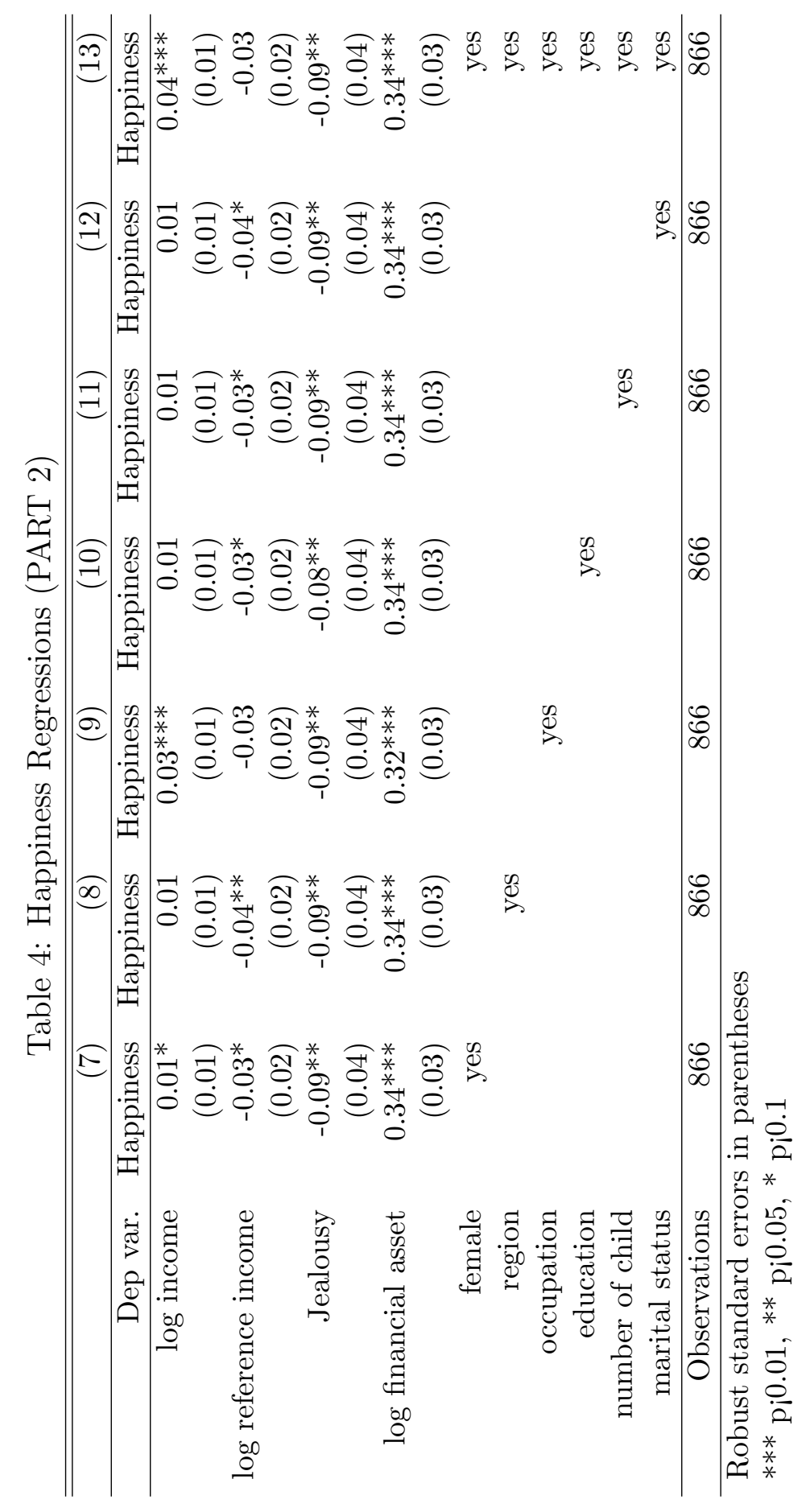




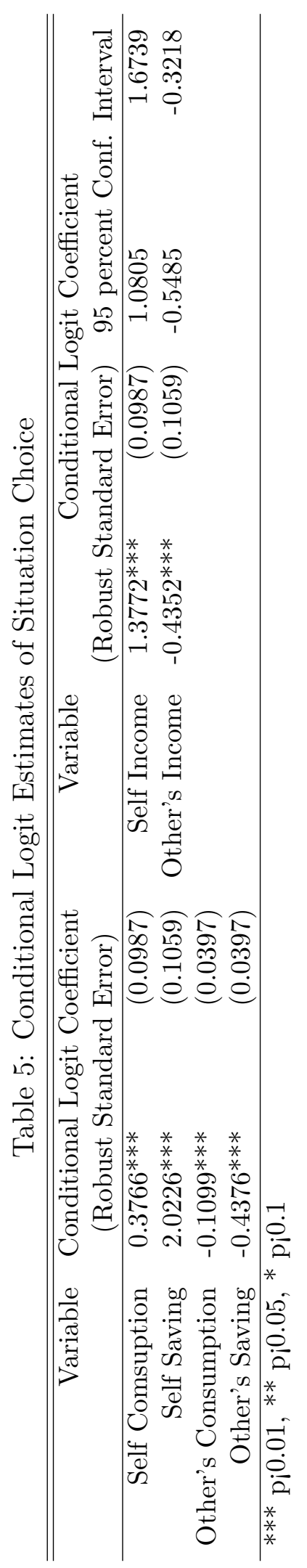


Table 6: Mixed Logit Estimates of Situation Choice

\begin{tabular}{|c|c|c|c|}
\hline Variable & $\begin{array}{l}\text { Mixed Logit Coefficient } \\
\text { (Standard Deviation) }\end{array}$ & Variable & $\begin{array}{c}\text { Mixed Logit Coefficient } \\
\text { (Standard Deviation) }\end{array}$ \\
\hline Self Comsuption & $0.4136^{* * *} \quad(3.0186)^{* * *}$ & Self Income & $1.7890^{* * *}$ \\
\hline Self Saving & $(2.9469)^{* * *}$ & Other's Income & $(1.2240)^{* * *}$ \\
\hline Other's Consumption & $-0.3492^{* * *}$ & & \\
\hline Other's Saving & $(0.8140)^{* * *}$ & & \\
\hline
\end{tabular}

*** $\mathrm{p}_{\mathrm{i}} 0.01,{ }^{* *} \mathrm{p}_{\mathrm{i}} 0.05,{ }^{*} \mathrm{p}_{\mathrm{i}} 0.1$ 


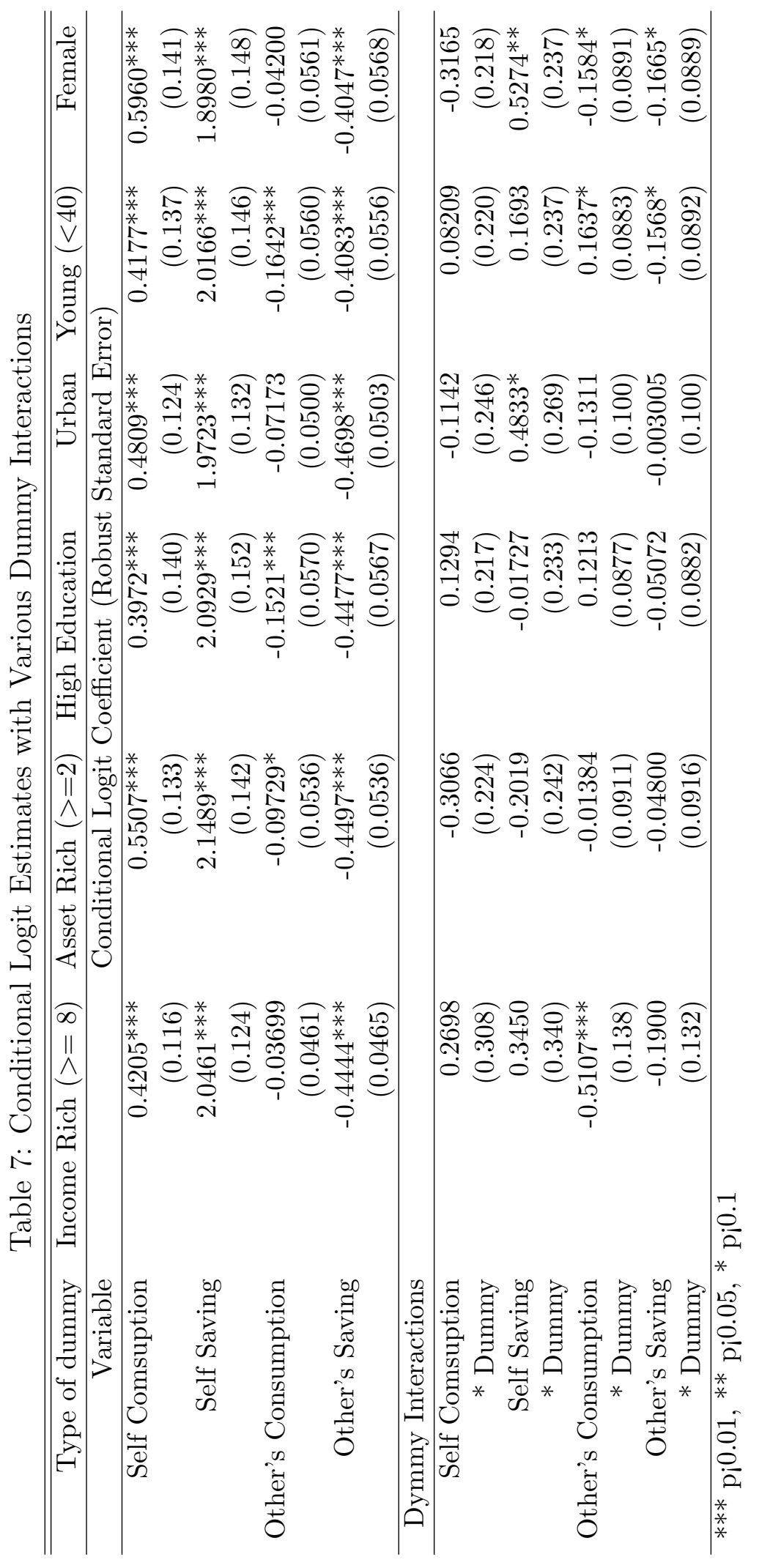




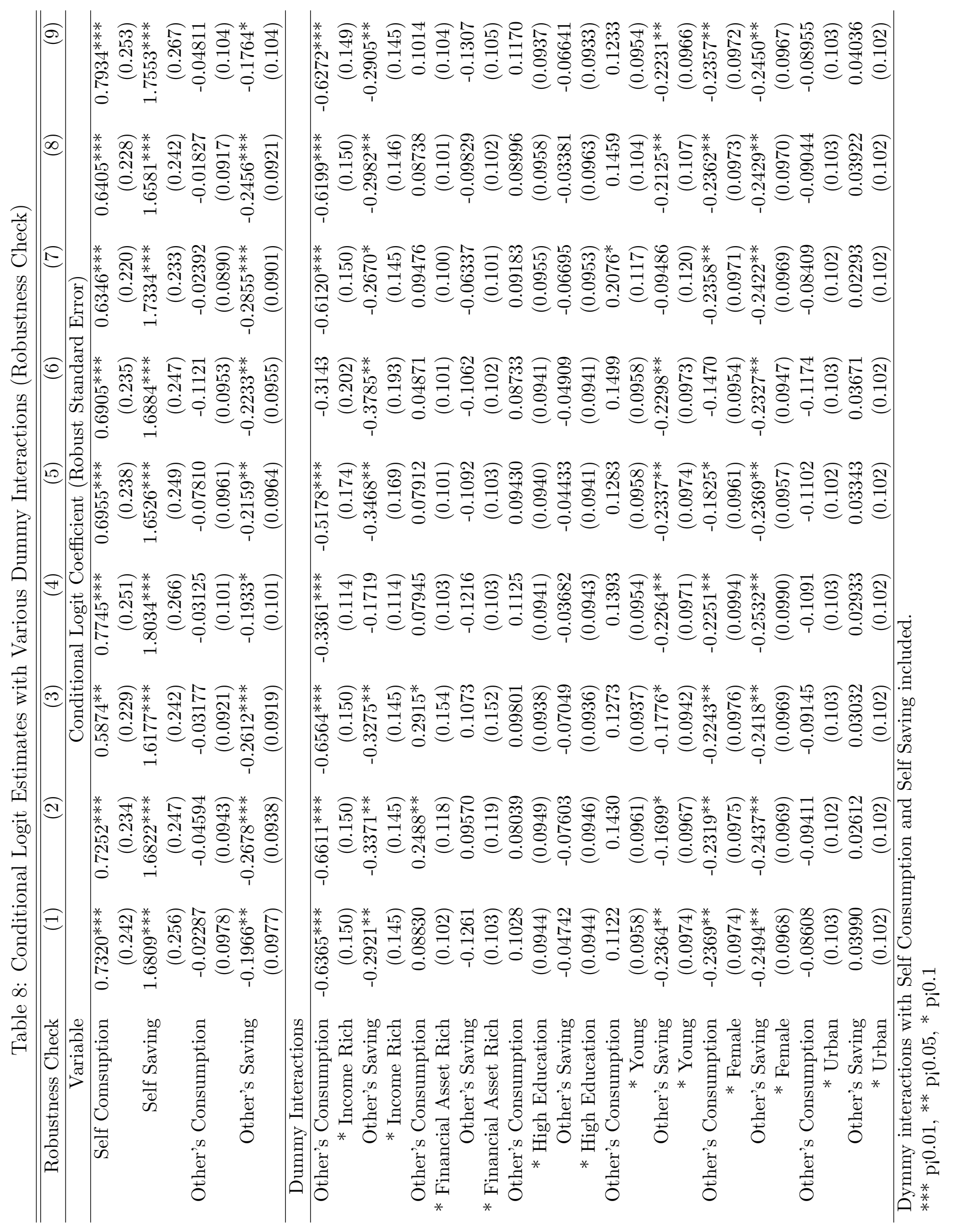


Table 9: Conditional Logit Estimates of Situation Choice: Subsample Analysis

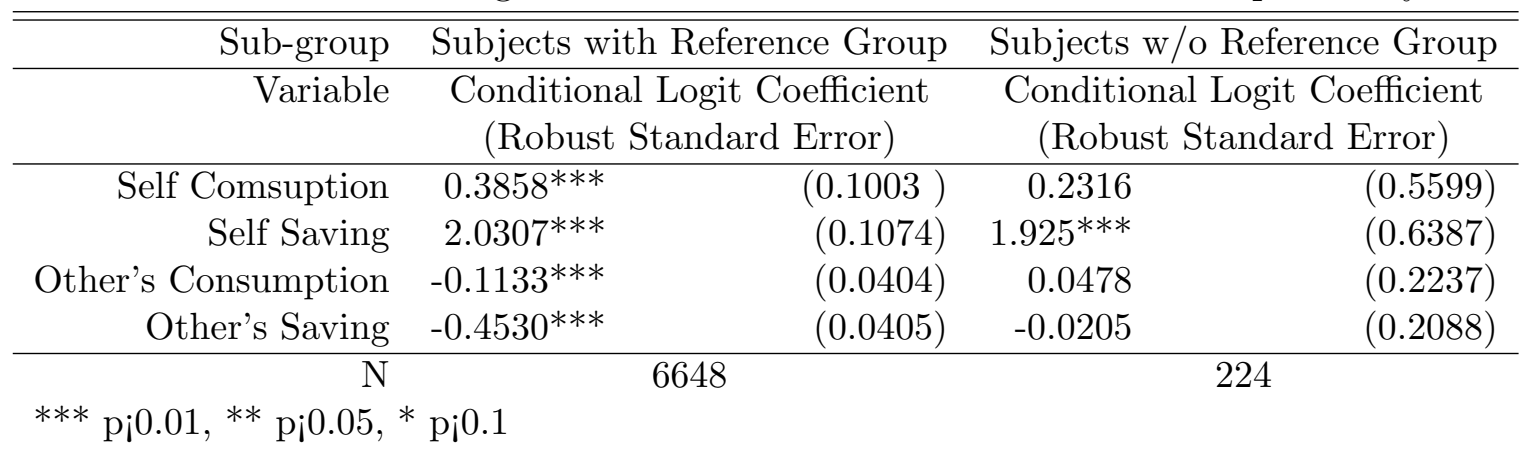

Table 10: Conditional Logit Estimates with Higher-Jealousy Dummy Interactions

\begin{tabular}{|c|c|c|c|c|}
\hline Type of dummy & \multicolumn{2}{|c|}{ Baseline } & \multicolumn{2}{|c|}{ Jealous } \\
\hline Variable & $\begin{array}{l}\text { Conditional } \\
\text { (Robust }\end{array}$ & $\begin{array}{l}\text { oefficient } \\
\text { Error) }\end{array}$ & $\begin{array}{l}\text { Conditiona } \\
\text { (Robust }\end{array}$ & $\begin{array}{l}\text { oefficient } \\
\text { Error) }\end{array}$ \\
\hline Self Comsuption & $0.3766^{* * *}$ & $(0.0987)$ & $0.4133^{* * *}$ & $(0.1154)$ \\
\hline Self Saving & $2.0226^{* * *}$ & $(0.1059)$ & $2.0630^{* * *}$ & $(0.1230)$ \\
\hline Other's Consumption & $-0.1099^{* * *}$ & $(0.0397)$ & $-0.0870^{*}$ & $(0.0462)$ \\
\hline Other's Saving & $-0.4376^{* * *}$ & $(0.0397)$ & $-0.3775^{* * *}$ & $(0.0462)$ \\
\hline Dummy interaction (SC) & & & -0.1286 & $(0.2241)$ \\
\hline Dummy interaction (SS) & & & -0.1374 & $(0.2431)$ \\
\hline Dummy interaction (RC) & & & -0.0867 & $(0.0913)$ \\
\hline Dummy interaction (RS) & & & $-0.2262^{* *}$ & $(0.0908)$ \\
\hline
\end{tabular}

*** $\mathrm{p}_{\mathrm{i}} 0.01,{ }^{* *} \mathrm{p}_{\mathrm{i}} 0.05, *{ }^{*} \mathrm{p} 0.1$

Table 11: Conditional Logit Estimates, Scope Test

\begin{tabular}{|c|c|c|c|c|}
\hline Variable & \multicolumn{4}{|c|}{$\begin{array}{l}\text { Conditional Logit Coefficient } \\
\text { (Robust Standard Error) }\end{array}$} \\
\hline Self Comsuption & $0.3766^{* * *}$ & $(0.0987)$ & & \\
\hline Self Comsuption 2 & & & -0.1033 & $(0.2426)$ \\
\hline Self Comsuption 3 & & & 0.0187 & $(0.4060)$ \\
\hline Self Comsuption 4 & & & -0.1174 & $(0.5224)$ \\
\hline Self Saving & $2.0226^{* * *}$ & $(0.1059)$ & & \\
\hline Self Saving & & & $0.7756^{* * *}$ & $(0.2361)$ \\
\hline Self Saving & & & $1.3112^{* * *}$ & $(0.4579)$ \\
\hline Self Saving & & & $2.3669^{* * *}$ & $(0.4590)$ \\
\hline Other's Consumption & $-0.1099 * * *$ & $(0.0397)$ & & \\
\hline Other's Consumption 2 & & & -0.1319 & $(0.1720)$ \\
\hline Other's Consumption 3 & & & -0.0638 & $(0.1544)$ \\
\hline Other's Consumption 4 & & & $-0.2855^{* * *}$ & $(0.0887)$ \\
\hline Other's Saving & $-0.4376^{* * *}$ & $(0.0397)$ & & \\
\hline Other's Saving 2 & & & -0.0415 & $(0.1513)$ \\
\hline Other's Saving 3 & & & $-0.4207^{* * *}$ & $(0.0973)$ \\
\hline Other's Saving 4 & & & $-0.2883^{* *}$ & $(0.1332)$ \\
\hline
\end{tabular}

